\title{
PENINGKATAN KEAHLIAN PEGAWAI \\ UNTUK PELAYANAN MASYARAKAT \\ DI DESA DAYEUH MANGGUNG KABUPATEN GARUT
}

\author{
Riffa Haviani Laluma ${ }^{1}$, Gunawan ${ }^{2}$,Teguh Nurhadi $\mathrm{S}^{3}$, Slamet Risnanto ${ }^{4}$, Gunawansyah ${ }^{5}$, \\ Bambang Sugiarto ${ }^{6}$ \\ 1,2,3,4,5,6 S1-Teknik Informatika, Fakultas Teknik, Universitas Sangga Buana
}

${ }^{1}$ korespondensi :riffa.haviani@usbypkp.ac.id

\begin{abstract}
ABSTRAK
Pengabdian kepada Masyarakat (PkM) merupakan salah satu kegiatan Tridharma yang dilakukan sebagai bentuk sumbangsih ilmu pengetahuan dan teknologi kepada masyarakat. Prodi S1 Teknik Informatika sebagai salah satu prodi yang fokus terhadap perkembangan dan penggunaan teknologi informasi berkewajiban memberikan program pelatihan komputer sebagai bentuk implementasi Tridharma perguruan tinggi. Pelaksanaan PkM pada tahuan akademik 2020/2021 dilaksanakan di desa Dayeuh Manggung kecamatan Cilawu kabupaten Garut provinsi Jawa Barat. Pelatihan komputer yang diberikan kepada pegawai kelurahan desa Dayeuh Manggung kecamatan Cilawu bertujuan agar para staf keluruhan mampu menggunakan software khususnya Microsoft Office Word dengan baik sehingga pekerjaan-pekerjaan administratif desa dapat dikerjakan dengan rapih, efisien dan tertib dalam pengarsipannya.
\end{abstract}

Kata Kunci: Komputer, Teknologi Informasi, Microsoft Word, Administrasi.

\begin{abstract}
Community Service (PkM) is one of the Tridharma activities carried out as a form of contribution of science and technology to society. The Informatics Engineering Study Program as a study program that focuses on the development and use of information technology is obliged to provide a computer training program as a form of implementation of the Tridharma of higher education. The implementation of PkM in the 2020/2021 academic year was held in Dayeuh Manggung village, Cilawu sub-district, Garut district, West Java province. The computer training provided to employees of the Dayeuh Manggung village, Cilawu sub-district aims to ensure that the entire staff is able to use software, especially Microsoft Office Word, so that village administrative work can be done neatly, efficiently and orderly in filing it.
\end{abstract}

Keywords: Computer, Information Technology, Microsoft Word, Administration.

\section{PENDAHULUAN}

Dayeuh Manggung merupakan desa yang berada di kecamatan Cilawu, kabupaten Garut, provinsi Jawa Barat. Desa yang berada pada ketinggian $900-1.150$ meter dpl ini mempunyai luas 436, $57 \mathrm{Ha}$. Desa

Dayeuh Manggung berbatasan dengan desa Karyamekar di sebelah utara, desa
Mekarsari di sebelah selatan, desa Dangiang di sebelah barat dan di sebelah timur berbatasan dengan kecamatan Cigalontang kabupaten Tasikmalaya. Suasana pertanian di desa Dayeuhmanggung dapat dilihat pada Gambar 1 berikut. 


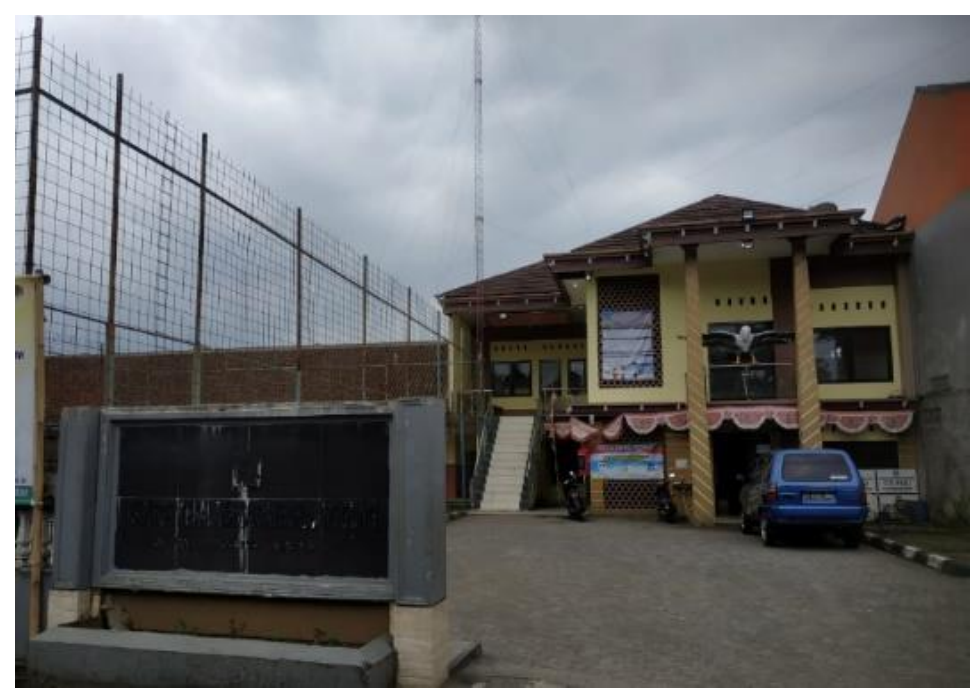

Gambar 1 : Desa Dayeuh Manggung

Pengembangan sumber daya manusia merupakan salah satu fungsi MSDM utama yang tidak hanya terdiri atas pelatihan dan pengembangan, namun juga aktivitasaktivitas perencanaan dan pengembangan karier individu, pengembangan organisasi, serta manajemen dan penilaian kinerja. Pelatihan dirancang untuk memberikan sejumlah pengetahuan dan keahlian yang diperlukan untuk pekerjaan yang dilakukan oleh seseorang dalam mendukung kinerja pribadi dan organisasi. [1]

Dalam kesehariannya pegawai desa dayeuh manggung masih kesulitan menggunakan tools yang ada pada microsoft word seperti mail merge atau perintah otomatis yang disediakan Microsoft word, padahal sangat banyak masyarakat membutuhkan surat keterangan dari desa, layanan administrasi kependudukan masih menggunakan cara konvensional dimana warga harus mengunjungi langsung ke kantor desa untuk mengurus pembuatan surat-surat kependudukan, dari desa dibuatkan dengan cara mencopy data tersebut untuk dibuatkan yang baru, bisa dibayangkan kalau dalam satu hari ada yang minta berbagai jenis surat ada 20 orang saja, pegawai desa bisa menyelesaikan minimal 8 surat dalam satu hari. Belum lagi untuk menulis pelaporan ke kecamatan dimana pegawai desa hanya mampu mengetik satu lembar/hari . Untuk itu perlu adanya peningkatan kinerja pegawai dari sisi keahlian pengolahan data untuk efisiensi dan efektifitas. [2]

Untuk itu para pegawai kelurahan harus mampu mengoperasikan komputer untuk melayani permohonan kependudukan dan juga untuk pelaporan yang baik untuk kelurahannya maupun untuk kecamatan Cilawu.[3]

Untuk itu kami dari Teknik Informatika, Fakultas Teknik, Universitas Sangga Buana melakukan pelatihan Microsoft Word guna membantu pegawai desa dalam melakukan pelayanan terhadap masyarakat.

\section{METODE}

Metode kegiatan dalam rangka pengabdian masyarat secara umum berbentuk pelatihan 
P-ISSN: 2745-5912

E-ISSN: 2745-9047

Microsoft Word selama 3 hari, dimana pelatihan tersebut memotivasi agar pegawai kelurahan mau belajar terus sesuai perkembangan teknologi yang terus berkembang.

Adapun workshop yang kami lakukan adalah sebagai berikut :

- Pengenalan personil dari prodi Teknik Informatika yang akan menjadi narasumber materi pelatihan Microsoft Word.

- Pengenalan Microsoft Word apa saja yang harus diketahui oleh pegawai desa

- Lurah Dayeuh Manggung menyediakan ruangan untuk pelatihan

- Lurah Dayeuh Manggung menyediakan komputer (laptop) untuk pegawainya
- Dari prodi Teknik Informatika mengadakan workshop Microsoft Word yang langsung dijelaskan oleh ketua pengabdian masyarakat dan diikuti oleh pegawai kelurahan dan didampingi oleh parodi Teknik Informatika.

\section{HASIL DAN PEMBAHASAN}

Pelaksanaan kegiatan pengabdian pada masyarakat bertempat di desa Dayeuh Manggung, kecamatan Cilawu, kabupaten Garut, secara rinci hasil kegiatan sebagai berikut :

1. Pengenalan personil dari prodi Teknik Informatika yang akan melatih Microsoft Word

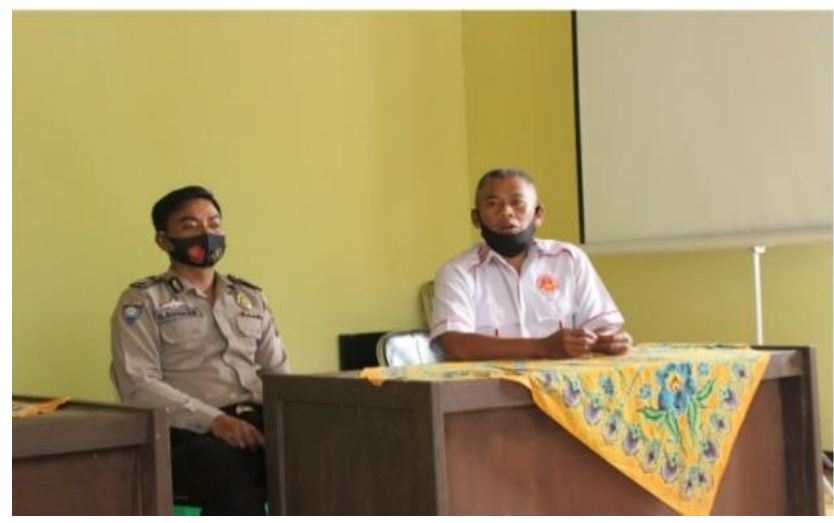

Gambar 2 : Pengarahan dari lurah Dayeuh Manggung

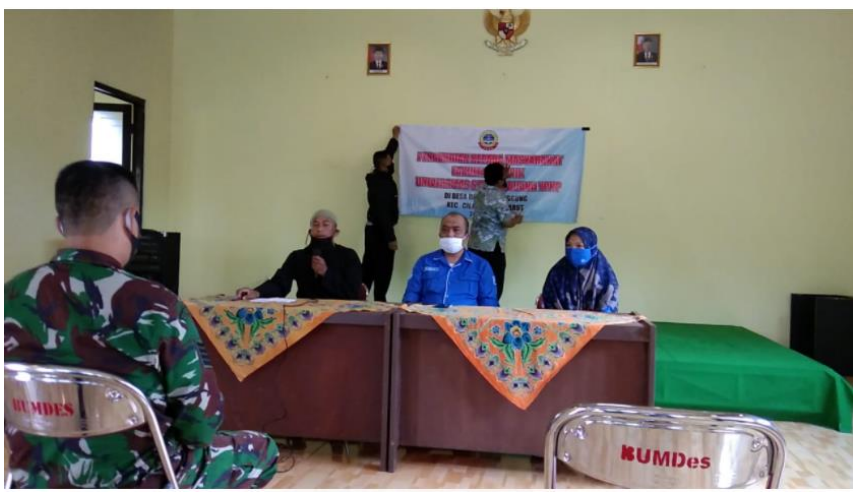

Gambar 3. Pengenalan dari Fakultas Teknik 
P-ISSN: 2745-5912

E-ISSN: 2745-9047

2. Dari prodi Teknik Informatika mengadakan workshop Microsoft Word yang langsung dijelaskan oleh diikuti oleh pegawai kelurahan dan ketua pengabdian masyarakat dan didampingi oleh parodi Teknik Informatika.

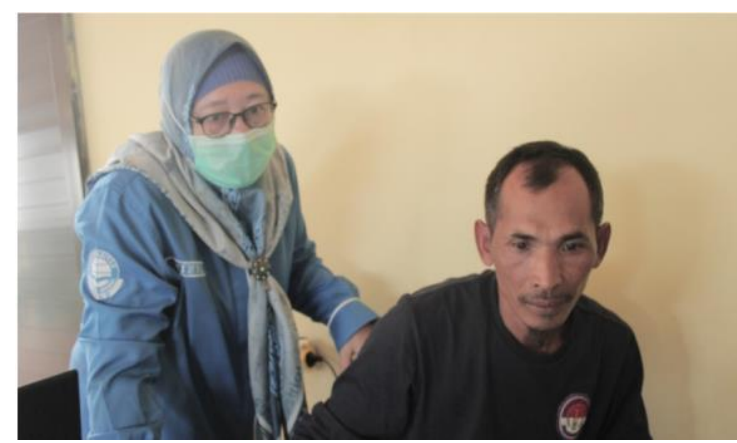

Gambar 4 : Pelatihan Microsoft Word bagi pegawai kelurahan

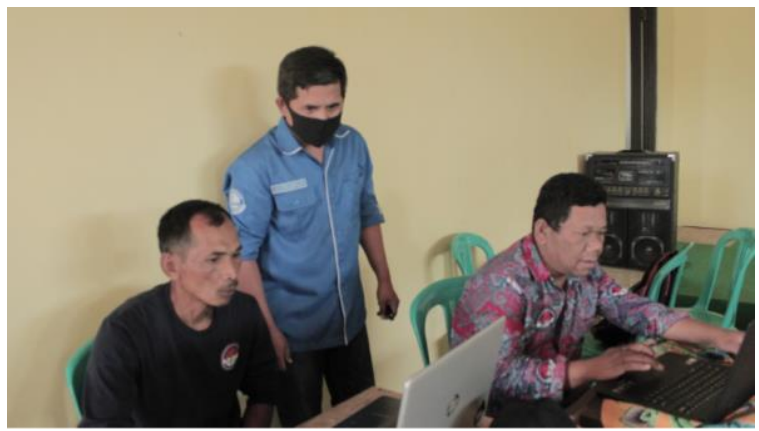

Gambar 5 : Pelatihan Microsoft Word dari Teknik Informatika

\section{Hasil Evaluasi Pelatihan}

Respon dari hasil pelatihan dan worshop ini sangat baik, terlihat dari hasil evaluasi berupa :

1. Dari hasil obrolan dengan pihak pegawai desa bahwa pelatihan ini sangat bermanfaat dan mereka minta untuk pelatihan lagi terutama Microsoft Excel.

2. Permintaan dari kepala desanya bahwa perlu berkelanjutan proses workshop pelatihan pegawai desa

3. Karena terkendala covid, jadi untuk berkelanjutan pelatihan Microsoft Word nya masih panjang namun kita harus terhenti dulu.

4. Rencana pelatihan berkelanjutan yang ingin kami adakan adalah Microsoft Word, Microsoft Excel dan Microsoft PowerPoint.

\section{PENUTUP}

Kegiatan pelatihan komputer bagi perangkat desa Dayeuh Manggung, kecamatan Cilawu, Kabupaten Garut dapat berjalan dengan lancar. Pelatihan ini sesuai dengan tujuannya yaitu membekali pemanfaatan secara maksimal penggunaan perangkat lunak Microsoft Office agar pekerjaan-pekerjaan administrasi yang dilakukan oleh perangkat desa dapat dilakukan secara rapih, cepat dan efisien dengan memanfaatkan fasiltas-fasiltas yang ada 
perangkat lunak Microsoft Word [4].

Setelah mendapatkan pelatihan, harapannya perangkat desa dapat mempraktekkan apa yang sudah diberikan agar pekerjaan-pekerjaan yang terkait dengan dokumen administrasi terdokumentasi dengan baik. Program pembinaan dan pendampingan kepada peserta pelatihan untuk menjamin keberlangsungan dan keberlanjutan hasil pelatihan PkM ini juga akan terus dilakukan dengan demikian kebermanfaatan pelatihan dapat terwujud sehingga pelayanan adminnistrasi kepada masyarakat dapat terwujud.

Bentuk upaya lain agar kegiatan pelatihan ini dapat berjalan pada periode berikutnya dirasa perlu ditindaklanjuti melalui kerjasama yang antara berbagai pihak, khususnya Perguruan Tinggi dan Pemerintah Daerah agar pelatihan komputer di wilayah lain bisa dilaksankan.

\section{DAFTAR PUSTAKA}

[1] Asih Niati, Anitiyo Soelistiyono, Teguh Ariefiantoro. "Pengembangan Kemampuan Sumber daya manusia melalui pelatihan computer Ms Office Exel untuk meningkatkan kinerja di desa Mrangggen

[2] Faidul Adzim, Eka Prabawati Rum. 2017. Sistem Informasi Desa di Kecamatan Pallangga Kabupaten Gowa. Jurnal Pengabdian Kepada Masyarakat, Vol. 1 Nomor 1.

[3] Asih Winantu. 2017. Modul Pelatihan Komputer "Microsoft Office Word Excel. Dapat diakses pada https://asihwinantu.files.wordpress.com /.../modul-pelatihan-komputerpustikom.doc.

[4] Asroni dan Haris Setyawan. 2016. Pelatihan MS Office dan Pembuatan Blog Di Dusun Kalitengah Lor, Glagaharjo, Cangkringan Sleman, dapat diakses pada http://repository.umy.ac.id/ bitstream/handle/123456789/3527/Pelat ihanMSOfficedanBlog08-2016. 